\title{
Business Negotiation Culture in China A Game Theoretic Approach
}

\author{
Yong Jiang ${ }^{1}$ \\ ${ }^{1}$ School of International Trade and Economics, Guangdong University of Foreign Studies, Guangzhou, China \\ Correspondence: Yong Jiang, School of International Trade and Economics, Guangdong University of Foreign \\ Studies, Guangzhou, China. E-mail: jiangyong@gdufs.edu.cn
}

Received: November 24, 2012

Accepted: December 17, 2012

Online Published: January 25, 2013

doi:10.5539/ibr.v6n3p109

URL: http://dx.doi.org/10.5539/ibr.v6n3p109

\begin{abstract}
There are numerous researches on the relationship between culture and business activities. Based on the Chinese negotiating culture, this paper utilizes game theory modeling method to summarize the major style of negotiations between Chinese businessmen and foreign businessmen. First, this paper analyzes the impact of culture on business negotiations, including priorities issues, negotiation strategy and negotiating style. Second, the paper puts forward the concept of "acculturation" in the analysis of cultural adaptability of Chinese businessmen, and it also clarifies the general as well as the potential reasons for the low acculturation for Chinese businessmen. Etiquettes for general business communications in China are also discussed in detail. In theoretical part, the paper analyzes negotiating sytle of Chinese businessmen with cultural characteristics. Due to the strategic feature of this model, a specific game theoretical model is built, and then a specific example of Chinese and foreign business price negotiations is used to show the applicability of the model. Finally, the article states the conclusions and direction for further research.
\end{abstract}

Keywords: business negotiaton, cross-culture negotiation, game theory, China

\section{Culture Influence on Business Negotiation}

Cultural values can be constituted on the basis of commercial negotiators' interests, so cultural differences generated by value preference may lead to cultural obstacles. The expectations of negotiators from different cultures may be inconsistent to each other's preferences, which can make them misunderstand each other's reasoning. Negotiators may try to persuade the other party to accept their own condition under pre-determined cultural understanding, while the distribution results are usually not ideal. The negotiators should seek trade-offs between differences and choice, and this is precisely the basis of integration on any agreement, which is the optimal choice when there are cultural differences between the two sides. They tend to come to a mutually satisfactory solution on the basis of maintaining their traditional culture preference.

People's negotiation behavior is generally strategic, and these strategies may be based on the culture. Culture makes social norms evolve gradually and the functional specification may institutionalize to promote social interaction within the same culture. When most people are using these norms, social interactions are more efficient. The research shows that a series of acts can be used when negotiators involve in confrontation and motivation strategy, among which cultural behavior of negotiators is one of the deciding factors. People from different cultures have different preferences facing the confrontation and use distinctive direct business language. Some cultures adapt to the negotiations by face-to-face communication, and cannot accustom to meet in the collective memories in a dispute or face-to-face confrontation. The relative importance of negotiators' own interests, other parties' interests and collective interests may be different in different cultures.

Tang and Lv (2009) points outs that the essence of business negotiation is a presentation of human relationship, so the habits, language arts and psychological demand has to be based on the specific culture. Mao and Xiao (2009) discuss the cultural resources of business negotiation and try to make strategies for the difference of thinking methods. There are also many game-theoretic studies of negotiations. For example, Asher et al (2001), Hashida (1996) focus on the conversation of two persons with perfect information. Parikh $(2001,2006)$ put more efforts on the information strategies of human interaction. However, these literatures determine the players' utility functions arbitrarily; their interactions are supposed to be mutually full understanding of each other. And they only analyze the simple example of one-short utterance and do not have cultural implications in the model. 
General speaking, they do not take full use of the game theory.

Application of game theory in conversation analysis (Asher et al., 2001; Parikh, 2006; van Rooij, 2006) involves a variety of different types of communication. The signaling model and other modified versions establish game theoretic models generally based on use single language interaction discourse, that is, a single dialogue. While in business negotiations, multiple interactions in communication accompanied with non-verbal information and show the dynamic and holistic characteristics. Pragmatic behavior is the combination of the discourse with paralinguistic features and context in a certain background and cultural factors are important elements of a context. Contextualization is formed through the process of negotiation, understanding and exclusion of the communicator in certain context. Communicative activities make contextual elements relevant, so the retention modification and cancellation of these elements can only be accomplished in a specific discourse.

Negotiating style is the magnanimity and general mode that demonstrated by the negotiators in the process of business negotiations, which is mainly reflected in behavior, manners, and ways control of the negotiation in the process, and negotiating style has deep cultural imprint. Culture not only determines the ethic code of the negotiators, but also affects the negotiator's way of thinking, personality and behavior. So the negotiators from different cultural backgrounds may form completely different style of negotiation, which has a direct impact on communication method, contacts and relations, and even negotiating structure during the negotiation process.

According to cultural differences, negotiating style can basically be divided into two types: Oriental negotiating style and Occidental negotiating style. From the point of view on the basic elements, there are significant differences in the concept of time, willingness to take risks, communication process, understanding, ethics and the rule of law. Different cultures have different view on what is time, what is its impact on negotiations and other issues. Compared with the Chinese culture, American culture pays special attention to the time, and time is regarded as a valuable resource. So business negotiations are focused on the theme, from a task to another task. In cross-cultural business negotiation, the differences in concept of time may lead to misunderstandings. Some cultures tend to cultivate a bureaucratic, conservative negotiating style, while some other culture encourages entrepreneurial negotiators, who are willing to take action and risks even under incomplete information. Position of taking adventure in specific culture may have significant impact on the content of the negotiations and its results. In risk-taking culture, negotiators are willing to reach an agreement as soon as possible, and to seize the opportunity as much as possible in the negotiations. In risk-adverse culture, negotiatiors tend to gather more information before making any decision and take a wait-and-see attitude. Though communications in the negotiation process mainly rely on verbal communication, non-verbal communication should not be ignored. Therefore, negotiators must also be concerned about the body language and action language in different cultures, and try to understand their communication habits. Differences in the etiquette is even more obvious, for example, Chinese people are not used to directly call out the name of others, but usually add a appropriate title (Mr., president, manager, professor, etc.), while directly calling each other names is very common in the culture of many other countries.

\section{Basic Knowledge for Business Negotiation with Chinese}

\subsection{Acculturation in China}

China has become increasingly important in frequent business transaction with other parts of the world, and Chinese businessmen encounter more and more cross-cultural problems in business negotiation. Depending on the degree of adaptation, acculturation can be classified as low acculturation, medium acculturation, and high acculturation. The low acculturation mainly refers to the situation that businessmen know less about each other's culture and language, so they use their mother tongue and traditional negotiating styles in the negotiations. They mainly rely on the translators in negotiations and stick to their own culture identity. In medium acculturation, businessmen both use their own traditional culture and also take into account each other's culture in the negotiations, and they are able to use each other's language fluently, and understand some nonverbal customs. They have a tolerant attitude towards cultural differences in negotiations, and cultural adaptation does not include changes in values and thinking. Businessmen of high acculturation tend to use other's culture and negotiating style in the negotiations, and they deliberately conduct the negotiations comprehensively in other's culture, so no local culture and way of thinking can be detached.

Chinese businessmen are quite different in the degree of cultural adaptation in cross-cultural business negotiation. In general, however, Chinese businessmen tend to be lower acculturation in business negotiations. It is difficult for them to fully adapt to the Western style negotiation and Western culture. The survey shows that there are some inadequacies for Chinese businessmen in cultural adaptation in the following aspects. (a) use of language. More than $69 \%$ of the businessmen may not negotiate intensive with foreign partners with a foreign 
language, and they are unskilled in technical terms and slang of negotiations and $48 \%$ of them rely mainly on translator in the negotiations. (b) Non-verbal communication. $87 \%$ of the businessmen do not understand the indication or body language for foreigners. (c) Values. $62 \%$ of the businessmen do not understand values of the West, and even less for the cultural practices. (d) Ways of thinking in negotiations, $51 \%$ of the merchant cannot accept direct Western culture, such as arguments based only on the facts and non-emotional style negotiations. (e) Negotiation strategy. $63 \%$ of the businessmen in the decision-making require a collective discussion, so it is difficult for them to make a personal decision.

Relatively low acculturation of Chinese businessmen is contributed to some deeper reasons, which includes the concept of "face" in China, the plot of Chinese language and cultural threat. In the Chinese business culture, "face" means the merchant's reputation and status, which has become a symbol of social value. "Face" reflects many aspects of social life, such as personal wealth, intelligence, appearance, status and the relationship of others, and sometimes face is more important for some people's personal life. Face can be earned, lost, and given away, but many Western businessmen are hard to understand. For example, if China CEOs make mistakes in business negotiations, Western businessmen may stressed that error face to face and this makes CEOs lose "face" in front of his subordinates, so Chinese CEOs would be certainly unhappy. From the point of view of language, English has become the dominant language of international business negotiations. Due to their language level, the Chinese businessmen tend to avoid using English. English may not express their true viewpoints and English may also affect their own communicative thinking. Chinese merchants are less likely to spend a lot of effort learning English, so they tend to turn to business translators. Cultural development is an inevitable invasion of the local culture. The current generation of businessmen in China is more loyal to their traditional culture and is consciousness against the erosion of alien culture.

\subsection{Basic Etiquette in China}

Etiquette culture in China has a long history, and the Chinese family education has always put emphasis on the learning and development of children's etiquette. Chinese culture generally following a few basic principles. (a) Principle of orders. In social interaction and social life, Chinese people pay attention to a certain order in social activities, in which people are all agree and social norms constrain the behavior of everyone. (b) Principle of appropriateness. Chinese people advocates a mind of "middle way", which means everything can neither be insufficient nor excessive. Chinese called it the "reasonable manner" not too humble or too arrogant, but it is more difficult to find a balance between these two. (c) Principle of morals. Etiquette and morality are used to regulate the relationship among the members of society and codes of conduct in social relations. Etiquette emphasis on behavior, while moral emphasis on personality and value cultivation. Chinese people rely more on interpersonal ethics to regulate and maintenance activities in social life and are relatively weak in the concept of law compared to Western culture. (d) Principle of humility. Humility stems from politely refuse in China and Chinese would not rushed out for the interests in other's person's face. Chinese culture cherish mutual respect in interpersonal relationships, so the traditional Chinese saying goes: "Step back and open the sky".

\subsection{Cultural Characters of Business Negotiation in China}

Chinese-style negotiations are based on the inheritance of traditional Chinese culture and learning from the West negotiation culture, which is generally regarded as the persuasive mode. The core of Chinese-style negotiations is to convince the other side from the psychological view, and to pay more attention to the process of negotiations, that is, focus on strategies instead of tactics in negotiations. Therefore, the application of strategy is an important feature of the Chinese negotiation culture. Application of game theory in the research of negotiation strategy reflects the formalized characteristics of Chinese negotiation culture. Traditional Chinese culture has a long history in the application of strategy, and many classic works focus only on the philosophy and principles, not for detailed and specific application areas. Negotiators are offered the guidance on the principles and concepts, but not detailed tactics. China's negotiators not only look forward to the outcome of negotiations, but also pay more attention to the process of negotiation. China negotiators are not necessarily strictly in accordance with the specified procedure of negotiations, while they always arrange some leisure activities, in order to understand each other to establish their own negotiating strategy at the same time. Similarly, harmonious and friendly relations between negotiators may promote the process of negotiation. For Chinese businessmen, result of negotiations is important for sure. However, if the negotiation process is not pleasant, it may affect the results of negotiation. For example, for the previously mentioned face problems, if foreign partner makes Chinese negotiators embarrassed or their face is threatened in the negotiations, though it is not an intentional move, it will make a tremendous loss to the negotiations.

In addition, another important principle is that the Chinese businessmen would adhere to the principles as well as 
be flexible in the negotiations. In China, the higher authority people tend to express their thoughts and ideas in a a more tactful and moderate way. They rarely refuse or deny to others in face, while they often smile and accompanied by a meaningful "nod". But "nod" does not necessarily mean the promise and agreement on the final decision; they may be reserved about immediate signature. This behavior cannot be regarded as fraud, so negotiator's "nod" does indicate that he is able to understand what you think, and to encourage the speaker continue to express the ideas, and at this time it does not mean that he agreed to follow each other's views and take action by your advice.

\section{General Game Theoretical Model of Negotiation}

The game theoretical model is built based on the constructed communication process, which include the internal representation of the game information. The important feature is the cultural identity of the communicator, which can be divided into background information and context information, respectively $K_{b}$ and $K_{s}$. Communication model $M_{b}$ contains a combination of the four factors $(N, K, \phi, G)$, where $N$ is the set of the negotiators, so $n \geq 1, K$ is communication context, $\phi$ is the set of sentences, $i \geq 1, G$ is the corresponding function term: $G: \phi \rightarrow K$, which means is context $K_{i}$ is assigned to the discourse $\phi_{i}$, compared to the initial context $K_{0}$. Considering cultural factors, $K_{b}$ means negotiators in the communication of their own language has culture consensus, $K_{s}$ means that negotiators have communicative intention for information exchange on discussion theme. Bilateral exchanges are competed by means of the following procedure: The basic function of $G$ is to assign discourse to achieve context updates by context $K$. If $C$ is based on their own beliefs of discourse $\psi_{c}$, and $F$ also communicate based on their cultural interpretation $\psi_{f}$, differences in cultural background may lead to mistakes in signal passing, which make decoding very difficult. Communicative act has been completed, but the communicative content and function may deviate in the process of communication, that is, communication process is the belief update of $H$. From the point of view on dynamic information, negotiation activities begin with the initial context $K_{0}$ and this initial context is closely related with the general cultural background of the negotiators. Context updates after the start of the negotiations becomes $K \oplus \phi$ and sequential discourse $\left(\psi_{c n}, \psi_{f n}\right)$, in which $(c, h \in N, n \geq 1) . \psi_{c n}$ updates $K_{0}$ to be new context $K_{1}$, and $\psi_{f n}$ updates $K_{1}$ to be $K_{2}$. Two negotiating parties reach the result agreed by both sides with joint efforts in the communication process, which is also the operation process of a psychological model and evolving process of a recognition model. This interactive process can be used in the following business negotiations for price bargaining. As an example, the communicative model $M_{b}$ will be explored.

C1: The price of the product has increased for two dollars, but we still make the original quotation unchanged.

F1: Thanks. I also know the increase of price, and I think it is a normal fluctuation. Your original price has exceeded the market price already. Even if you keep that price, we cannot accept it.

C2: When we offered the price, we made it very clear that if there's any change on the market our quotation will follow. But what happened now is that the market price has gone up and our quotation has not changed. This means our price has actually decreased, right?

F2: True, But compared with the real market price, your quotation is still too high.

C3: If you really insist on your price, it'll be very difficult to proceed with our talk.

F3: Let's not rush to the conclusion yet. Even if my price can change for some degree, the different between us is too great.

C4: No matter how great the different is, you'll have to move. And we can move together, okay? You are not expecting me to make a move alone.

F4: (Thinking about this proposal for a while) All right then, I'll add 50 cents.

The extensive game is used to describe the above contents of negotiations. The game tree of this negotiation process shows that Chinese businessman $C$ and foreign businessman $F$ may have better choice in this round of price negotiations. Negotiations proceed smoothly to achieve the purpose of negotiation, and every dialogue is the subgame perfect in the game, to achieve a balanced result in the sequential condition. Equilibrium path is the realization path in the game tree, including reaction when participants deviate from the path. The subgame perfect equilibrium needs to reach the conditions of all possible paths, including the main path of the negotiations and all subgame branch paths. On each conversion point, businessmen have to optimize their behavior and to consider the possible consequences of the hidden meaning of their own discourse, so they are sequentially rational. However, communication process can be divided into two sub-processes: characterized process and expression process. From the point of view of characterized process, $C$ is converted into language, which is correlated with the amount of controlled information and cultural habits. But this process is generally 
implied and difficult to observe. The expression process is to convert language and ideas into sound information, so this process is often observed. Cultural factors have a significant impact on these two processes.

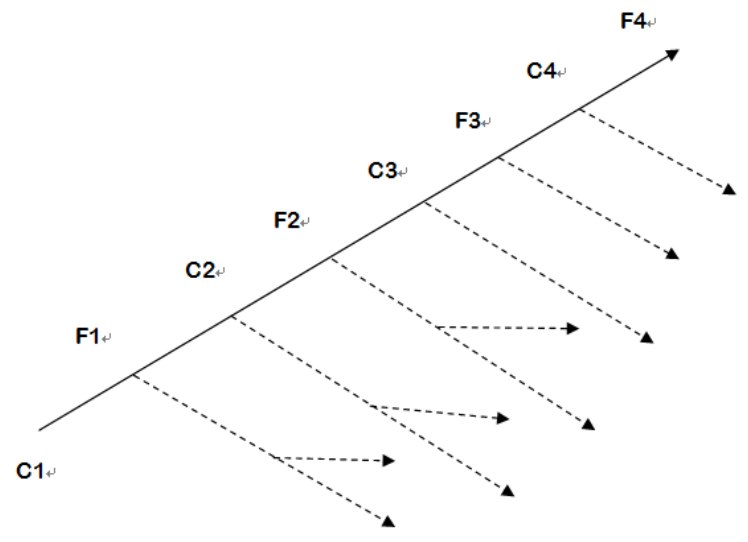

Figure 1. The game tree of a negotiation in price bargaining

Description: Dotted line and arrow paths mean other possible ways negotiators may choose.

In the above example of business negotiations, two sides both hold certain information on price, but they exchanges ideas on the level implied meaning. The subgame perfect equilibrium path in this game is backwards induction. The players choose the optimal action at each node from the terminal node and proceed backwards to the root of the game tree. In this general model, the paper does not quantify the utility function of $C$ and $F$, nor discusses other options at other node. These two tasks are more complex, which will not be discussed in this paper. However, such talks is very common in business negotiations between Chinese and foreign businessmen, which is a specific description of the culture in Chinese business negotiations. Firstly, $C$ states their reasonable quotations are based on recent market price increases, and $F$ also knows the information of prices and responds that it is a reasonable market price fluctuation. Then $C$ begins to emphasize that his quotation is reasonable, stating that his offer is fixed and market prices are rising, which is the equivalent of a disguised price cuts. $F$ puts forwards that the offer is already very high, regardless of the market price. In the third round, $C$ tries to control the change of context. If the other party does not show flexibility, negotiations may not proceed. In such a situation, $F$ shows certain looseness. Finally, $C$ inspires awareness and positive emotions of the other party. Eventually, $F$ choose to make concessions, which contributed to the agreement of two sides in accept the way. Basically, the above process can be expressed as:

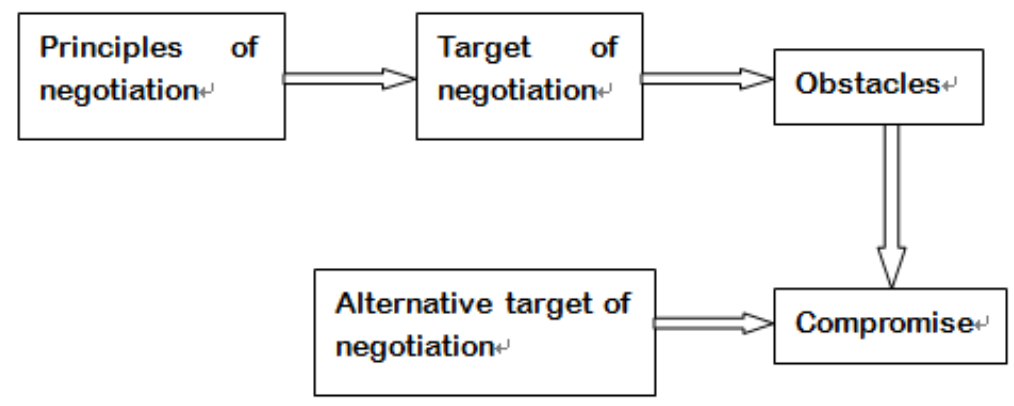

Figure 2. The persuasive negotiating style in Chinese culture

The game model $M_{n}$ is based on a three-factor sub-game set. $\Pi$ is a the communicative set, and in this paper $\Pi=[1,2]$, which represents two persons' dialogue. If $n=1$, it refers to monologue of the communicator. The present model defines a two-person model, and $n$ is an arbitrary natural number. Considering the characteristics of negotiating behavior and the simplicity for calculation, this communicative negotiation model set $n$ to two. Collection of behavior can be defined as $\Omega=I * Q$, and $I$ represents the set of illocutionary forces and $Q$ represents of declarative sentences. Meaning of $I$ is the description of act itself, while from the philosophical point of view, $Q$ is the effective behavior under description, and it is the finite set of huge numbers. The set of strategies can be defined as $\Omega_{i}=\Omega_{m}$, which $\forall \mathrm{i} \in N, m$ is the number of moves in the games. Utility function 
can be defined as $U c$ and $U f$, and $U i: \Omega i \times \Omega m \rightarrow \square(i, m \in N, i \neq m)$. Utility function may be propositional or a functional. In sequential game, information is obviously imperfect and incomplete, which is the basis for negotiators to optimize their own actions at every node, and they are Bayesian rational. Communicative set itself contains many elements, while this model is considering cross-cultural negotiations of the two persons. The game tree in this model based on the fact that each player has to move one after another and action in $\Omega$ is possible at every turn. The information set contains only one node (perfect information). $Q$ is a limited round of dialogue, and the actual dialogue has the characteristics of short-term memory. $Q$ includes not only the correct sentence but also wrong sentence. If $S$ is a false expression, then it is defined as telling a lie.

Using the above definition, the sequential conversation can be restated as $\mathrm{C} 1$ : offering $\rightarrow \mathrm{F} 1$ : explaining $\rightarrow \mathrm{C} 2$ : answering $\rightarrow$ F2: stating $\rightarrow \mathrm{C} 3$ : threatening $\rightarrow$ F3: rebounding $\rightarrow$ C4: requesting $\rightarrow$ F4: accepting. The basis of the dialogue is subgame perfect interaction along the equilibrium development path, $C, F$ can reach the optimal utility:

$$
\begin{aligned}
& U_{c}^{n} \text { (offering, answering, threatening, requesting) } \\
& +U_{f}^{n} \text { (explaining, stating, responding, accepting) } \\
& \geq U_{c}^{n}\left(\zeta_{c}, \zeta_{f}\right)+U_{f}^{n}\left(\zeta_{c}, \zeta_{f}\right)
\end{aligned}
$$

In which, $\forall \zeta_{c} \in \Omega_{c}, \forall \zeta_{f} \in \Omega_{f}, C, F \in N, \zeta_{c}, \zeta_{f}$ refer to other possible actions that $\mathrm{C}$ and $\mathrm{F}$ may take in current situation. The actions of $C$ and $F$ based on their strategy and the response is associated with cultural factors.

Sequential equilibrium path is related with the sequence of action. The negotiators should first consider the expected utility of their actions. Then observe each other's actions to update their own point of view and optimize the actions. Correctly decoding each other's words is the prerequisite of the formulation of this strategy, and discourse decoding and cultural identity are related. In general game model, we generally assign a real number to represent the action and calculate the payoff generated by payment and consistency of both parties from the payment.

In the above model, the sequential equilibrium of the game and its path associated with the sequence of actions of negotiating party are used to calculate the expected payoff of the action, while follower also needs to update their own beliefs based on the actions optimize action of the former. Firstly, the communicative game proceeds under the state of asymmetric information, with the nature of limited information between the two sides. Negotiators are from different cultural backgrounds, so their communication bound to be bounded rational. So the business negotiation is a process of asymmetric coordination. Secondly, coordination is the focus of the negotiation language and cultural barriers make some understanding of discourse fail to restore the true value, while it is only a reasonable approximation of the intention of $S$. Finally, the payments of the coordinated action have a different understanding for the communicators. Their utility function is generally not a consensus, with the function depending on the quality and quantity of information, as well as the way of the action.

The model should be more practical under the constraints of node selection, which profoundly related to the cultural patterns of select groups on each node. Static analysis may not fully reflect the negotiation process, so part of the scene dialogue can be simulated by the computer program. The main difference between computer programming analysis and game theory is reflected in the utility function. Behavior can be defined for determined status of the operation each time, and each node of the game tree represents its location in the game, so the computer program is a manifestation of the theoretical game model. The direct usage of Computer programming in conversation analysis is very difficult, because the dynamic process of dialogue is affected by cultural factors. However, the Bayesian game and signaling game can be successfully applied in an imperfect information game.

\section{Conclusion and Discussion}

It is worth noting that contemporary Chinese negotiation culture has integrated the traditional "deductive" thinking style in China, and it also gradually absorbs "inductive" feature of Western negotiating culture, which form the brand new "Chinese business negotiation style". On the major issues, negotiators tend to take the "deductive" style, which is a step-by-step negotiation; on the minor issues, flexible "inductive" style is applied, which are straightforward and quick in problem-solving. The negotiation style of Chinese businessmen can be summarized as persuasive negotiation style and its main mode is to convince people with psychological forces. The main mode can be: analysis, implication passion, orientation and control. The intent of this negotiation style is: firstly, negotiators analyze the specific business environment and situation, and point out each other's situation with possible gains and losses, which can motivate positive emotions and make the partner agree with 
their point of view in the negotiators. Then, this will control the direction of negotiation on certain issue and control the psychological intention of the other side, which eventually make the other side agree on a certain kind of negotiated solution. That is why the Chinese businessmen tend to focus on the psychological advice or intangible capacity in negotiation.

This paper also analyzes the generally applicable style between Chinese and foreigners in business negotiations, and portrays possible negotiation strategies in game theory under imperfect information. Game model and computer programming are both feasible ways in research. Utility functions in the model are left open, which is a very important advantage. Different utility function can be derived from different dialogue model, which provides analytic framework and foundation for analysis of the cross-cultural negotiations. The structure of analysis is relatively complete, reflecting the complete equilibrium path and game tree, which includes the whole process from the opening statement to the ending statement. This general description of the model can be applied to negotiations between different cultures, and the theoretical framework of game theory can be used in different disciplines, including game theory, microeconomics, game programming, artificial intelligence, and pragmatics as well as discourse analysis. The model analyzes a series of negotiation process with interactive nature, rather than a single round of dialogue analysis. In order to improve its accuracy, the model must be considered as a whole, because a single dialogue may produce more or less cost in negotiations, and the payment of two sides in the understanding of dialogue depends on their utility function, the entire dialogue game as well as other factors. The model also focuses the conversation in turn, which obviously has some limitations. The negotiations may possibly contain a lot of overlaps and intervenes, so the game tree in the model needs reconsideration. Further analysis can extend to the specific negotiation style and explore optimal results of negotiation. In addition, artificial intelligence methods with computer simulations utilized in negotiations is also a direction of this study. In-depth analysis may also collect additional corpus, which can be summed to consistent results for negotiations.

\section{Acknowledgments}

The research is supported by China Postdoctoral Science Foundation funded project and Education Research Project for Young Schoars in Guangdong University of Foreign Studies (GWJYQN11001).

\section{References}

Asher, N., Sher, I., \& Williams, M. (2001). Game-theoretical foundations for Gricean constraints. In R. van Rooy \& M. Stockhof (Eds.), Proceedings of the $13^{\text {th }}$ Amsterdam Colloquium (pp. 31-37). Amsterdam.

Camerer, C. F. (2003). Behavioral Game Theory: Experiments in Strategic Interaction. Princeton: Princeton University Press.

Dekker, P., \& Van Rooy, R. (2000). Bi-directinal optimality theory: an application of game theory. Jounal of Semantics, 17, 217-242. http://dx.doi.org/10.1093/jos/17.3.217

Ellison, G. (2000). Basins of attraction, long run equilibria, and the speed of step-by-step evolution. Review of Economic Studies, 67(1), 17-45. http://dx.doi.org/10.1111/1467-937X.00119

He, N. (2011). Case Study on the influence of Chinese traditional philosophy to the enterprise management. Journal of Management and Strategy, 2(3), 73-76. http://dx.doi.org/10.5430/jms.v2n3p73

Jager, G. (2000). Some notes on the formal properties of bidirectional optimality theory. Journal of Logic, Language and Computation, 11, 427-451. http://dx.doi.org/10.1023/A:1019969702169

Kuhn, H. W. (1997). Classics in Game Theory. Princetion: Princeton University Press.

Levinson, S. (2000). Presumptive Meanings: The Theory of Generalized Conversational Implicature. Cambridge, Mass: MIT Press.

Metha, J., Starme, C., \& Sugden, R. (1994). The nature of salience: an experimental investigation of pure-coordination games. The American Economic Review, 74, 658-673.

Parikh, P. (2006). Radical semantics: a new theory of meaning. Jounal of Philosophical Logic, 35, 349-391. http://dx.doi.org/10.1007/s10992-005-9017-4

Pietarien, A. V. (2003). Games as formal tools versus games as explanations in logic and science. Foundations of Sceince, 8, 317-364. http://dx.doi.org/10.1023/A:1026319711838

Rabin, M. (1990). Communication between rational agents. Journal of Economic Theory, 51, 144-170. http://dx.doi.org/10.1016/0022-0531(90)90055-O

Sally, D. (2003). Risky speech:behavioral game theory and pragmatic. Journal of Pragmatics, 35, 1223-1245. http://dx.doi.org/10.1016/S0378-2166(02)00170-4 
Selten, R. (1975). Reexamination for perfect equilibrium points in extensive games. International Journal of Game Theory, 4, 25-55. http://dx.doi.org/10.1007/BF01766400

Van Rooij, R. (2004). Signalling games select Horn strategies. Linguistics and Philosophy, 27, 493-527. http://dx.doi.org/10.1023/B:LING.0000024403.88733.3f

Van Rooij, R. (2006). Different faces of risky speech. In Benz, A., G. Jager, \& R. van Rooij (Eds.), Game theory and Pragmatics (pp. 152-173). Palgrave Macmillan. 